\title{
Double Burden of Malnutrition among Freshman University Students: Determinants and Correlates
}

\author{
Amany A Salama, Naglaa M Ismael and Nesrine A Helaly
}

Faculty of Allied Medical Sciences, Pharos University in Alexandria, Egypt

\begin{abstract}
Background: The double burden of malnutrition (DBM) is marked by simultaneous presence of obesity and undernutrition or non-communicable diseases within persons, families, and/or communities. The concept that freshmen experience significant weight gain upon entering a university setting along with exacerbation of bad dietary habits can be alarming. Objectives: To evaluate the prevalence of dyslipidemia, anemia and elevated blood pressure, over-weight and obesity as indicators of DBM - among a sample of freshman students in Pharos University in Alexandria (PUA) and identify associated factors. Method: A sample of 214 students' volunteers was surveyed using a questionnaire to gather information about demographic and lifestyle data. Anthropometric and blood pressure measurements were taken and after 12 hours of fasting collected blood samples were assayed for blood count ( $\mathrm{CBC})$, lipid profile and fasting plasma glucose. Results: Overweight and obesity 44\% (35\% \& 9\% respectively), and abdominal obesity $25.2 \%$ were found with no significant differences between sexes. Prevalence of anemia among females was $(27.3 \%)$ compared to $(4 \%)$ in males. Prevalence of overall dyslipidemia was $21 \%$, high TC $13.3 \%$, high TG 1.4\%, a high LDL 12.5\%, and a low HDL 19.6\%. Elevated blood pressure showed a prevalence of $30 \%$, and was significantly associated with added salt. Conclusion: DBM at individual and community levels was prevalent in the current study, in the form of anemia with overweight / obesity and some cardiovascular risk factors among this community with disproportionate affection of females with reference to anemia.
\end{abstract}

Key words: Double burden of malnutrition, freshman, dyslipidemia in Egypt, anemia, cardiovascular risk factors

Corresponding author: Amany A Salama E-mail: amanysalama@hotmail.com

\section{Introduction}

The double burden of malnutrition (DBM) is a challenging issue in Egypt. Addressing DBM is a key to achieving sustainable development goals. ${ }^{1}$ Egypt is suffering from an under-five community with malnutrition. The adult population in Egypt is also struggling with a burden of malnutrition as $28.5 \%$ of females of reproductive age suffer from iron deficiency anemia and $20 \%$ of adult females suffer from diabetes along with $16 \%$ of males. In the meantime $41 \%$ of females and $23 \%$ of males (32\% total) are obese. $^{2,3}$
DBM may exhibit at three levels. Firstly, two types of malnutrition occur simultaneously at individual level, e.g., obesity with nutritional anemia, or vitamin or mineral deficiencies and inadequacies. It also can happen in the entire life span because of different dietary factors that are triggered by a change in economic conditions or other situations, such as overweight for a person formerly affected by stunting. Secondly, malnutrition occurs at household level e.g., an anemic mother with a child or a grandparent with overweight or diabetes. This is common 
in middle-income countries with rapid nutrition transition. Lastly, DBM is also seen in communities, with undernutrition, overweight and obesity or non-communicable diseases (NCDs) in the same group, area or country, with disproportionate affection of women at the population level. ${ }^{1}$

Youth are the adult population of tomorrow, and their well-being and health are vital. Their transition to university life is seen as a chronic stress, and exacerbates bad dietary habits with frequent consumption of high-fat, highcalorie foods and less fruit and vegetables each day. In adaptation to university, freshmen face the risk of excessive weight gain due to sedentary habits including the use of computer, social media and TV watching. The weight gain of freshman students may be five times that of the public at large. ${ }^{4,5}$

Young adulthood is a risky time for the development of malnutrition, either over or under nutrition; particularly for anemia, especially in females and/ or obesity-related risk factors as dyslipidemia and elevated blood pressure; exposing them to DBM. ${ }^{6,7}$

Egypt is one of many countries that witnessed an epidemiological transition in recent decades and can be explained by many factors; the best relevant is diets as they clarify dysmetabolic diseases. Cardiovascular diseases (CVD), cancer, and diabetes, for example, are the frequent death triggers during this transition. ${ }^{3,8}$

This nutrition transition includes poor dietary habits, globalization, urbanization, and the excessive use of media including television, video games that have promoted dysmetabolic diseases including obesity, metabolic syndrome, diabetes, insulin resistance and risk factors for cardiovascular disease. $^{9}$

Among adults in Egypt a $36 \%$ and $10 \%$ elevated cholesterol and fastingtriglyceride is found and nearly half the death rates are due to CVD. This is an outcome of the nutritional transition and augmentation of risky attitudes, including unfit obese people and rising smoking level. ${ }^{3,10}$

Anemia is a state of diminished hemoglobin or red blood cells, under a certain cut off value, resulting in exhaustion and pallor. ${ }^{11}$ Anemia in Egypt is a crucial burden affecting 30\% of females in the age of reproduction. In pregnant females anemia is one of the principal causes of childhood anemia. Faulty iron intake or absorption among youth are the primary causes of anemia; resulting from an iron-poor diet, increased iron requirement, and persistent blood loss due to monthly losses among females. ${ }^{12}$ In addition to poor feeding habits triggered by concern about body image; the condition is exacerbated by females ' menstrual losses. ${ }^{13}$

Cholesterol level at the age of 22 was reported to predict the hazard of acquiring CVD in the next 30 to 40 years. ${ }^{14}$ Around a quarter of adults in low-income countries had a rise in total cholesterol and surged to approximately one third in both sexes in countries with low middle income as Egypt. ${ }^{15}$

After literature reviewing, we found that studies in Egypt are scarce to measure the prevalence of dyslipidemia among university students especially in the second capital of Egypt (Alexandria); and has little information on the predominance of nutrition-related risk factors among young people and the DBM among this critical community of future parents and mothers to be.

The aim of this research was to estimate the prevalence of dyslipidemia, anemia and elevated blood pressure as well as overweight and obesity - as indicators of DBM - and risky eating behaviors in a sample of freshman university students in Pharos University in Alexandria 
(PUA) and to compare the indicators in males vs. females.

\section{Method}

During the period from April to June 2018; a sample of 214 volunteering freshmen (84 males \& 130 females) from Faculty of Allied Medical Sciences (FAMS) were surveyed. Using a 95\% confidence level to detect an over $30 \%$ prevalence of obesity in adult Egyptian ${ }^{3}$, the required sample size was found to be 233 subjects. $^{16}$ But as students were volunteering and consenting for blood testing 214 was the number recruited.

Three steps were taken to collect data. The first step was to complete the questionnaire and the second was anthropometric measurements. Each student was assessed by weight, height, waist circumference and blood pressure. The third step was biochemical measurements and analysis.

Questionnaire for Socio-demographic and Eating behavior: A questionnaire was designed for collecting data from each student concerning the cultural and demographic attributes, eating habits and intake. A simplified questionnaire on the frequency of consuming food groups was used to ask for dietary intake. The pattern of consumption of various foods as well as the most commonly consumed beverages emphasizing meat, poultry and dairy products, fish, legumes, number of servings of fruit and vegetables were recorded. As well as data about diet, exercise, sleep, and stress eating were collected.

Anthropometric Measurements: Body mass index (BMI) was determined after measuring height and weight. All measurements and waist circumference were carried out according to the criteria described by Gibson. ${ }^{17}$

Two blood pressure readings, five minutes apart, measured using sphygmomanometers and average was taken.

Biochemical measurements: After a $12 \mathrm{~h}$ fast, blood samples were collected to be examined for complete blood count (CBC) (URIT 2900 plus-Auto Hematology Analyzer - China), FBS, total cholesterol, triglycerides, HDL, and LDL (Cobas 6000 c501 - Chemistry Analyzer - Roche Diagnostics, Germany).

Indicator Definitions and Specifications: $\mathrm{TC} \geq 200 \mathrm{mg} / \mathrm{dl}$ for hypercholesterolemia, $\mathrm{TG} \geq 150 \mathrm{mg} / \mathrm{dl}$ for hypertriglyceridemia, HDL $<40 \mathrm{mg} / \mathrm{dl} \delta$ and $<50 \%$ for low HDL, and LDL $\geq 130 \mathrm{mg} / \mathrm{dl}$ for high LDL. TG $\geq 150 \mathrm{mg} / \mathrm{dl}$ and $\mathrm{TC}<200$ $\mathrm{mg} / \mathrm{dl}$ was considered as isolated hypertriglyceridemia and Low HDL for $\hat{O}$ and $q$ without hypercholesterolemia or hypertriglyceridemia was considered as isolated low HDL ${ }^{(18)}$.

Central obesity was defined as waist circumference for Middle Eastern countries ( $\geq 94 \mathrm{~cm}$ in $\hat{\sigma}$ and $\geq 80$ in 9 ). Elevated blood pressure was defined as a systolic $\mathrm{BP} \geq 130 \mathrm{mmHg}$ and/or a diastolic $\mathrm{BP} \geq 85 \mathrm{mmHg}$. $\mathrm{FBG} \geq 100$ $\mathrm{mg} / \mathrm{dL}$ was an indicator of elevated fasting blood sugar (FBS). ${ }^{19}$

Regular physical activity was defined as participation in moderate or vigorous activity for $\geq 30$ minutes/day \pm 5 days/ week. ${ }^{10}$ Anemia was defined as $\mathrm{Hb}$ concentration $<12 \mathrm{~g} / \mathrm{dl}$ for females and < $13 \mathrm{~g} / \mathrm{dl}$ for males. ${ }^{11}$

Frequent fast consumption is considered with \pm 3 times/ week consumption of foods as fries, hamburger, and pizza. ${ }^{(20)}$

\section{Ethical consideration}

The research was carried out in compliance with the guidelines developed by the Ethics Committee of the PUA for human subject's research and the Ethics Committee has reviewed and approved the proposal. All measures and data obtained were kept confidential in accordance with data protection procedures. After they were told of the intent and protocol of the study, each student signed a written informed consent.

\section{Statistical analysis}


Statistical Package for Social Sciences software SPSS 20.0 (Chicago, Illinois, US) was the tool of analysis. Data have been checked, computed and presented in terms of frequency, percent and mean \pm standard deviation (SD). Categorical data were evaluated using a Chi square test and the student's $t$ test was used to determine difference between means and ' $\mathrm{p}$ ' values $<0.05$ were considered statistically significant.

\section{Results}

Table (1) shows the main characteristics of participating students, eating habits and some risk factors. 35\% had family history of health problems (Diabetes mellitus-CVD- Hypertension). Current smoking prevalence was low $3 \%$.

Elevated blood pressure $\geq 130 / 85$ was prevalent in freshmen by $30 \%$ with no differences among gender. Elevated fasting blood sugar was not prevalent among our studied sample.

Distribution of the studied sample according to BMI and anemia by gender in Table (2), range of BMI was 17.53 41.52 ( 2\% underweight, 55\% normal weight, and (44\% overweight and obese); $35 \% \& 9 \%$ respectively), abdominal obesity in $25.2 \%$ with no significant differences between sexes.

Table (3) shows the mean blood indices and dyslipidemia among males and females freshman students. Anemia prevalence in this age group was significantly higher among female students $(27.3 \%)$ when compared with their male counterparts (4\%). But the mean value of the blood indices was close to normal reference values. Overall dyslipidemia of the studied sample was $21 \%$, high TC $13.3 \%$, high TG $1.4 \%$ (isolated), high LDL $\geq 130 \mathrm{mg} / \mathrm{dl} 12.5 \%$. While LDL $\geq 100 \mathrm{mg} / \mathrm{dl}$ was $45 \%$ among males and females freshman students and low HDL reached $19.6 \%$ (7\% of which was isolated).

Significant association of blood pressure and added salt was detected.

We attempted associations and correlations between the prevalence of dyslipidemia, anemia and elevated blood pressure, no associations were found with the fathers' or the mothers' education. We also attempted associations and correlations between BMI and TV watching \& media using time as well as BMI and skipping breakfast, but none reached statistical significance.

Table (1): Some demographic data, risk factors and eating habits of the studied sample

\begin{tabular}{|c|c|}
\hline Variables & Descriptive \\
\hline Mother's education & College $64.8 \%$ \\
\hline Father's education & College $70.9 \%$ \\
\hline Family history of health problems & (DM-CVD- Hypertension) 35\% \\
\hline Breakfast daily & $25 \%$ \\
\hline Sweets \& Desserts daily & $52.1 \%$ \\
\hline Fizzy drinks 1-2 daily & $68.2 \%$ \\
\hline Fries daily & $65.7 \%$ \\
\hline Delivery daily & $68.6 \%$ \\
\hline Eating when stressed or in a bad mood & $71.6 \%$ \\
\hline Added Salt & $69.3 \%$ \\
\hline Vegetables Daily ( $\geq 2$ servings) & $56.4 \%$ \\
\hline Fruits Daily ( $\geq 2$ servings) & $56.4 \%$ \\
\hline Physical activity (30 min.) Daily & $56.1 \%$ \\
\hline TV Watching \& Media Using Time & One hour $10 \%$ \\
\hline TV Watching \& Media Using Time & $2-3$ hours $30 \%$ \\
\hline TV Watching \& Media Using Time & More than 3 hour $60 \%$ \\
\hline Current Smoking including Shisha & $2.8 \%$ \\
\hline
\end{tabular}




\begin{tabular}{lr}
\hline Fish weekly (once-twice-trice) & $56.3 \%-32.6 \%-5.2 \%$ \\
\hline Pulses weekly (once-twice-trice) & $60.7 \%-20 \%-9.3 \%$ \\
\hline Dairy weekly (once-twice-trice) & $58.1 \%-19.9 \%-5.9 \%$ \\
\hline Meat \& Poultry weekly (once-twice-trice) & $6.5 \%-22.3 \%-35.3 \%$ \\
\hline
\end{tabular}

Table (2): Distribution of the studied sample according to BMI and anemia by gender

\begin{tabular}{|c|c|c|c|c|c|c|c|}
\hline \multirow{3}{*}{ BMI } & \multicolumn{4}{|c|}{ Sex } & \multirow{3}{*}{$\begin{array}{c}\text { Total } \\
\mathrm{n}=214 \\
\%\end{array}$} & \multirow{3}{*}{ Test of Sig. } & \multirow{3}{*}{ p } \\
\hline & \multicolumn{2}{|c|}{$\begin{array}{c}\text { Male } \\
(\mathbf{n}=\mathbf{8 4})\end{array}$} & \multicolumn{2}{|c|}{$\begin{array}{l}\text { Female } \\
(n=130)\end{array}$} & & & \\
\hline & No. & $\%$ & No. & $\%$ & & & \\
\hline$<18.5$ (Underweight) & 2 & 2.3 & 3 & 2.3 & 2.3 & & \\
\hline 18.5 - 24.9 (Normal weight) & 42 & 50.0 & 77 & 59.0 & 54.5 & $Y^{2}-3177$ & \\
\hline $25-29.9$ (Over weight) & 34 & 40.4 & 37 & 28.7 & 34.55 & $x=3.4 / 2$ & 0.324 \\
\hline$\geq 30$ (Obese) & 6 & 7.3 & 13 & 10.0 & 8.65 & & \\
\hline No anemia & 81 & 96 & 95 & 72.7 & 84.35 & $X^{2}-1005$ & $00001 *$ \\
\hline Anemia & 3 & 4 & 35 & 27.3 & 15.65 & $x=19.03$ & 0.00014 \\
\hline
\end{tabular}

Table (3) Mean blood indices and lipid profile values among males and females freshman students

\begin{tabular}{lrrr}
\multicolumn{1}{c}{ Blood indices } & $\begin{array}{c}\text { Males }(\mathbf{n}=\mathbf{8 4}) \\
\text { Mean } \pm \text { SD }\end{array}$ & $\begin{array}{c}\text { Females }(\mathbf{n}=\mathbf{1 3 0}) \\
\text { Mean } \pm \text { SD }\end{array}$ & \multicolumn{1}{c}{ (p value $)$} \\
\hline Hemoglobin $(\mathbf{g} / \mathbf{d l})$ & $14.01 \pm 1.64$ & $12.21 \pm 1.57$ & $(0.0001)^{*}$ \\
\hline Hematocrit $\mathbf{\%})$ & $40.42 \pm 2.64$ & $38.25 \pm 2.75$ & $(0.0001)^{*}$ \\
\hline MCV (fl) & $88.03 \pm 9.13$ & $84.74 \pm 9.46$ & $(0.012)^{*}$ \\
\hline MCH (pg) & $28.38 \pm 0.87$ & $27.25 \pm 0.64$ & $(0.0001)^{*}$ \\
\hline TC & $185.2 \pm 44.1$ & $184.9 \pm 40.3$ & 0.96 \\
\hline TG & $125.9 \pm 53.6$ & $127.1 \pm 36.5$ & 0.84 \\
\hline LDL & $111.7 \pm 51.6$ & $110.2 \pm 38.9$ & 0.81 \\
\hline HDL & $42.9 \pm 11.2$ & $44.1 \pm 8.7$ & 0.38 \\
\hline
\end{tabular}

Student t-test, *: Statistically significant at $p \leq 0.05$.

$M C V$ : mean corpuscular volume, MCH: mean corpuscular hemoglobin.

\section{Discussion}

In a way to estimate the prevalence of dyslipidemia, anemia and elevated blood pressure among young adults, a total of 214 freshmen volunteers (84 males \& 130 females) from the Faculty of Allied Medical Sciences were recruited in a cross sectional study. In this current work, we encountered $42 \%$ overweight and obese; $33 \%$ \& $9 \%$ respectively; this was almost in line with the WHOObesity and overweight fact sheet and Mediterranean region prevalence, as well as a previous work $^{21}$ among the same population.

Recent data from STEPwise Survey 2017 showed $\sim 36$ percent obesity rate, $(\sim 49$ percent) female prevalence and almost $80 \%$ of Egyptians are not physically active. Most Egyptians have recorded low consumption of fruit and vegetables. $^{22}$

A recent study in Sohag reported 38.5\% overweight and obesity that was more common among female students. Positive correlations were being physically inactive, excessive consumption of soft drinks and being married as students favored fatty foods over vegetables and fruits. ${ }^{23}$

We reported $38.7 \%$ over-weight/ obesity in females compared to $47.7 \%$ in males. We assumed that women would be more over-weight than men, but this has not been the case. Our 
results corresponded to previous studies (21) as well as some recent research in Kuwait, (24) where more men than women were overweight or obese ( $55 \%$ and $39 \%$ ); nevertheless, the fast food intake was not distinguished across sex or body mass index.

Though more men than women were overweight or obese, yet the consequences in females -future mothers to be- are more alarming. Masterson et al reported that about 20\% of overweight/obese Egyptian mothers had a minimum of one child stunted, $5.1 \%$ had a minimum of one child underweight and $3.2 \%$ had both a stunted and underweight child. ${ }^{7}$

The prevalence of risk factors in childhood and adolescence for NCDs are known to augment the vulnerability to cause adult diseases. The screening for dyslipidemia in teenagers and young adults is particularly important when it comes to elevated risk of obesity and overweight. Non-optimal rates of high LDL and low HDL cholesterol were confirmed to be independently correlated with coronary heart disease (CHD) in young adulthood, two decades later. The evaluation of the prevalence will help reduce expense by identifying a fundamental modifiable risk variable for CHD. ${ }^{25-26}$ Visceral adiposity, obesity and over- weight, are considered as significant risk factors of dyslipidemia $^{27-28}$ we demonstrated abdominal obesity in $25.2 \%$.

It remains a controversial topic whether the consequence of skipping breakfast affects health, especially in adults. One study indicated the nutritional and weight advantages of breakfast intake, in particular those containing grains, cereals, whole fruit and skimmed milk, as opposed to probable negative impacts of skipping. ${ }^{29}$

In a study examining the association between breakfast frequency and the 10-year risk of atherosclerotic CVD among Koreans respondents that never ate breakfast were much more probable to be in the high-risk group compared to respondents who ate breakfast $>5$ times per week. In particular, the risk for women and those with family record of CVD was higher. ${ }^{30}$ In another study, skipped breakfast was seen in 33\% of participants with MS, but no differences between body weight, dietary quality, nutrient intake and biochemical parameters were found. The research did not support the theory of impacting body weight, nutritional intake or biochemical parameters among MS participants by skipping breakfast. ${ }^{31}$

In the $75 \%$ who skipped breakfast in current work, there was no association with BMI and there were no differences between genders. As among this age group, it may be difficult to distinguish traditional breakfast, lunch or dinner, as skipping meals and frequent snacking became more prominent in university setting.

Positive correlations were reported in many studied between weight status and television (TV) and/ or video watching in children and youth. ${ }^{32-33}$ Inactive manners among youth e.g. free time computer use and TV viewing could be hazardous triggers for obesity and/ or over-weight. ${ }^{34}$ Prolonged use of internet has augmented the duration of daily inactive behavior in university students. In Bahrain; $\sim 80 \%$ of health science university students use the Internet $\pm 3 \mathrm{~h}$ a day. ${ }^{35}$ TV watching \& media using time more than 3 hour was reported by $60 \%$ of our study subjects. The lack of association reported in the present study between BMI and TV watching and/ or use of social media could be because these behaviors were routine among most adolescents belonging to all weight groups.

An increasing amount of scientific information supports an atherosclerotic cycle that starts in infancy and is a growing health issue in obese teenagers. Significant indicators for this 
progression are visceral fat and resistance to insulin. The full characterizing of atherogenic dyslipidemia mechanisms in teenagers may help to identify safe and effective prevention and therapeutic tactics and as such reduce associated cardiovascular health problems later in life. ${ }^{36}$ Dyslipidemia has been shown to increase the hazard of CVD mortality and considered as an independent preventable risk factor of $\mathrm{CHD}^{37}$ Accordingly, the study on the various indicators and risk factors of dyslipidemia appears to be significant in future health outcomes.

Typically dyslipidemia is distinguished by high levels of total cholesterol, triglycerides, low density lipoprotein, and diminished high density lipoprotein levels; the dyslipidemia prevalence among our study participants was $21 \%$ for overall dyslipidemia, a high TC of $13.3 \%$, high TG was $1.4 \%$ (isolated), a high $\mathrm{LDL} \geq 130 \mathrm{mg} / \mathrm{dl}$ of $12.5 \%$, while LDL $\geq 100 \mathrm{mg} / \mathrm{dl} 45 \%$ and a low HDL of $19.6 \%$ (7\% isolated). The difference between genders in the occurrence of dyslipidemia was not significant in this young age group. This indicates that the prevalence of dyslipidemia among freshman students in Alexandria is considerably lower than other governorates in Egypt.

This was in line with the STEPwise 2017, indicating lower percentage of hypercholesterolemia; 19.2\%; which comprises a major difference between results from the earlier STEPwise 11$12 .^{38}$

A research in Fayoum Governorate, Southern Egypt has shown that dyslipidemia in healthy university students was $\pm 64 \%$, hypercholesterolemia $\pm 39 \%$, hypertriglyceridemia $\pm 30 \%$, high LDL $\pm 33 \%$ and low HDL $\pm 27 \%$. ${ }^{39}$ Significant dyslipidemia factors were urban residency, higher age, physical inactivity, obesity, abdominal obesity, regular fast-food utilization and low intake of vegetable and fruit amongst study participants. In fact, their results appear to be higher when matching their findings with similar studies in youth; e.g. dyslipidemia in Kuwait was 10.6 percent for undergraduate students. ${ }^{40}$ Hypercholesterolemia was 15.6 percent among a group of 16-30 years old college students in Oman. ${ }^{41}$ As well as, in Sudan, $7.8 \%$ of freshman students had the metabolic syndrome phenotype. $^{42}$

Our current findings were in line with some earlier studies, in Egypt, one have found high TC, TG, LDL and low HDL prevalence at $6 \%, 7,5 \%, 8,2 \%$ and 9,4\%, respectively. ${ }^{43}$ The 2015 EHIS recorded a prevalence of 36.7 percent and 10.2 percent of hypercholesterolemia and hypertriglyceridemia, respectively, in people aged 15 to 65 years. ${ }^{3,10}$

An improvement in lipid profile has been demonstrated with exercise, as with physical activity, mostly triglyceride levels are decreased and HDL is raised. ${ }^{4-45}$ Performing regular exercise was high; physical activity (30 min.) daily was found in 56\% of subjects, this could be the reason behind low prevalence of hypertriglyceridemia in our study subjects. Daily vegetable intake has been identified before to be a protective factor against dyslipidemia. ${ }^{46}$ Daily vegetable intake of 2 servings was found in $56 \%$ of our study subjects. In another large survey evaluating 2900 students from 10 public universities in 10 governorates; the prevalence of diabetes and hypercholesterolemia in their study group was as well below adult Egyptian population; $0.4 \%$ and $8.3 \%$ respectively and reported obesity and overweight to have prevalence of $\sim 11 \%$ and $28 \%$ respectively, while abdominal obesity was shown in $\sim 43 \%$. In South Upper Egypt, female students were more abdominally obese. Approximately $2 \%$ 
have been hypertensive and $15 \%$ have been pre- hypertensive. Most students were nonsmokers and the minority exercised regularly. They concluded that abdominal obesity and prehypertension were prevalent in Egyptian youth. $^{47}$

A study in Alexandria, Egypt, stated that key determinants of high BP were both general obesity and central obesity in Egyptian adolescents. ${ }^{48}$ There was significant association of hypercholesterolemia with systolic and diastolic hypertension in previous studies, ${ }^{49}$ but currently a cause effect relationship cannot be appraised in this study.

The prevalence of anemia in our freshmen was significantly higher among female students (27.3\%) when compared with their male counterparts (4\%); and this was in accordance with the latest national data. ${ }^{3}$ Overweight and obese people may need increased intakes of nutritional iron in conjunction with nutritionally enhancing agents to maintain a balanced iron state and decreased inflammatory process related to obesity to ensure proper iron absorption. ${ }^{50-51}$

Situation analysis provides insights into where previous interventions could be effective by calculating rates and patterns in exposures to risk factors and the associated disease burden, and outlines current public health priorities. $^{52}$ Egypt is currently developing approaches for particular risk factors including cigarettes and poor diet. It does not however have a systemic integrated approach for controlling and preventing NCD.

\section{Conclusion}

This is amongst the few studies that dysmetabolic risk factors prevalence among young adults in Egypt is discussed. DBM at individual and community levels was prevalent in our study, in the form of anemia with overweight / obesity and dysmetabolic risk factors among this community with females disproportionately affected. Fluctuations observed in participants dietary habits can be related to changes in diet, sleep and stress levels. More in depth understanding of these challenges will help to combat the youth obesity epidemic and its dysmetabolic consequences.

\section{Future Directions}

Interventions to enhance physical activity and promote healthier diet between students should be deemed a priority to minimize their future risk for chronic diseases. Promoting wellness and preventative care aimed at screening, diagnosing and handling these risks should also be provided. Efforts to protect youth from the sophisticated advertising of sedentary activity and energy-dense, nutrients-poor foods and drinks must now be improved.

Limitations: Though this research included volunteers not a random sample, from one university which may not be representative for all university students in Egypt, however, it indicates current knowledge and information about the DBM in the form of anemia with overweight / obesity and dysmetabolic risk factors among this community.

\section{Acknowledgment}

We are grateful to the participating students at PUA for their valuable contribution.

\section{Funding}

We are grateful to the Board of Trustees at PUA for their support and financial contribution.

\section{Author Disclosure Statement}

All authors have no conflict of interest.

\section{References}

1. WHO (2017) The Double Burden of Malnutrition. Policy brief. Geneva: World Health Organization. (http://www.who.int/nutrition/publications/d 
oubleburdenmalnutrition-policybrief/en/, Accessed June 2017).

2. The double burden of malnutrition. Case studies from six developing countries. FAO Food and Nutrition Paper 84. Rome: Food and Agriculture Organization of the United Nations; 2006 (ftp://ftp.fao.org/docrep/fao/009/a0442e/ a0442e00.pdf, accessed 6 March 2017).

3. Ministry of Health and Population- 2015 Egypt Health Issues Survey (EHIS), October 2015. In collaboration with: El Zanaty and Associates, USAID, UNFPA and UNICEF.

4. Zaheer S, Imam SF, Imam N, Sikandar M, Bukhari MH. Assessment of dietary intake and physical activity pattern of adult girls students. Biomedica. 2017; 31(3):232-8. 5. Mihalopoulos NL, Auinger P, Klein JD. The Freshman 15: is it real? J Am Coll Health. 2008; 56(5):531-533.

6. Koszewski W, James K, Jones G, Rudy J. Assessing Dietary Intake Eating and Exercise Attitudes and Fitness Levels in College - Aged Students. Journal of the American Dietetic Association, 2011; 111 (9): A98.

7. Masterson AR, Sipsma H, Bradley E. The nutrition transition in Egypt: the double burden of over- and undernutrition at the household level examining mother-child pairs. The FASEB Journal. 2013; 27:1_supplement, 1b346-lb346.

8. NCD Risk Factor Collaboration (NCDRisC). Worldwide trends in body-mass index, underweight, overweight, and obesity from 1975 to 2016: a pooled analysis of 2416 population-based measurement studies in 128.9 million children, adolescents, and adults. The Lancet. 2017; 390(10113): 26272642.

9. Galal MO. The nutrition transition in Egypt: obesity, undernutrition and the food consumption context. Public Health Nutr. 2002; 5(1A): 141-148. doi: 10.1079/PHN2001286

10.WHO and ARE-Ministry of Health \& Population: Egypt National STEPwise Survey of Non Communicable Diseases Risk Factors 2011-2012.

11.WHO. Global nutrition targets 2025: anaemia policy brief (WHO/NMH/NHD/14.4). Geneva: World Health Organization; 2014.

12.Maternal and Child Nutrition Study Group-Maternal and child nutrition: building momentum for impact, The Lancet. 2013; 382: 373-375

13. Manios Y, Moschonis G, Chrousos GP, Lionis C, Mougios V, Kantilafti M, et al. The double burden of obesity and iron deficiency on children and adolescents in Greece: the Healthy Growth Study. J Hum Nutr Diet. 2012; 26: 470-478 doi: 10.1111/jhn. 12025

14. Washington RL. Interventions to reduce cardiovascular risk factors in children and adolescents. Am Fam Physician. 2009; 59(8): 2211-2218.

15.WHO- NCDs risk factors (cholesterol) https://www.who.int/gho/ncd/risk_factors/ch olesterol_text/en/ (Accessed March 2017).

16.Israel GD. Determining sample size, PEOD6, Agricultural Education and Communication Department, Florida Cooperative Extension Service, Institute of Food and Agricultural Sciences, University of Florida, Gainesville, lectures, 1992. Available at: http://edis.ifas.ufl.edu/pd006.

17.Gibson RS. Principle of nutrition assessment. Second edition. Oxford: Oxford University Press; 2005.

18.Expert Panel on Detection, Evaluation, and Treatment of High Blood Cholesterol in Adults. "Executive Summary of the Third Report of the National Cholesterol Education Program (NCEP) Expert Panel on Detection, Evaluation, and Treatment of High Blood Cholesterol in Adults (Adult Treatment Panel III)," The Journal of the American Medical Association. 2001; 285(19): 24862497.

19. Alberti KG, Eckel RH, Grundy SM, et al. Harmonizing the metabolic syndrome: a joint interim statement of the Inter-national Diabetes Federation Task Force on Epidemiology and Prevention; National Heart, Lung, and Blood Institute; American Heart Association; World Heart Federation; International Atherosclerosis Society; and International Association for the Study of Obesity. Circulation. 2009; 120: 1640-1645. 20.Le Bodo Y, Paquette MC, De Wals P. (2016). Reasons for Specifically Targeting Sugar-Sweetened Beverages. In: Taxing Soda for Public Health. Springer, Cham. doi. 10.1007/978-3-319-33648-0_2

21.Genena DM, Salama AA. Obesity and Eating Habits among University Students in Alexandria, Egypt: A Cross Sectional Study. 
World Journal of Nutrition and Health. 2017; 5 (3), 62-68.

22.WHO and ARE-Ministry of Health \& Population: Egypt National STEPwise Survey of Non Communicable Diseases Risk Factors 2017 Fact Sheet. (accessed at August 2018)

https://www.who.int/ncds/surveillance/ste ps/Egypt_STEPS_Survey_2017_Fact_Sheet.p df?ua $=1$

23. Abdou FS, Hamed AF, Mohammed ER, Mohammed NA. A Study of Prevalence of Obesity among Female Students in Sohag University. SOHAG MEDICAL JOURNAL. 2018; 22: 297-311.

24. Shaban L, Alkazemi D. Trends in Fastfood Consumption among Kuwaiti Youth. Int J Prev Med. 2019; 10:44. doi:10.4103/ijpvm.IJPVM_480_18.

25.Galhotra A, Abrol A, Agarwal N, Goel NK, Gupta S. Life Style Related Risk Factors For Cardiovascular Diseases In Indian Adolescents. Internet J Health 2009; 9(2).

26.Pletcher MJ, Bibbins-Domingo K, Liu K, et al. Nonoptimal lipids commonly present in young adults and coronary calcium later in life: the CARDIA (Coronary Artery Risk Development in Young Adults) study. Ann Intern Med 2010; 153(3):137-46.

27.Feingold KR, Grunfeld C. Obesity and Dyslipidemia. [Updated 2018 Apr 10]. In: Feingold KR, Anawalt B, Boyce A, et al., editors. Endotext [Internet]. South Dartmouth (MA): MDText.com, Inc.; 2000. Available from: https://www.ncbi.nlm.nih.gov/books/NBK3 05895/

28.Klop B, Elte JW, Cabezas MC. Dyslipidemia in obesity: mechanisms and potential targets. Nutrients. 2013; 5(4):12181240.

29. O'Neil CE, Nicklas TA, Fulgoni VL 3rd. Nutrient intake, diet quality, and weight/adiposity parameters in breakfast patterns compared with no breakfast in adults: National Health and Nutrition Examination Survey 2001-2008. J Acad Nutr Diet. 2014; 114(12 Suppl): S27-S43.

30.Lee HJ, Jang J, Lee SA, Choi DW, Park EC. Association between Breakfast Frequency and Atherosclerotic Cardiovascular Disease Risk: A CrossSectional Study of KNHANES Data, 2014-
2016. Int J Environ Res Public Health. 2019; 16(10):1853.

31.Zhang L, Cordeiro LS, Liu J, Ma Y. The Association between Breakfast Skipping and Body Weight, Nutrient Intake, and Metabolic Measures among Participants with Metabolic Syndrome. Nutrients. 2017; 9(4):384.

32.Steffen LM, Dai S, Fulton JE, Labarthe DR. Overweight in children and adolescents associated with TV viewing and parental weight: Project HeartBeat!. Am J Prev Med. 2009; $\quad 37(1 \quad$ Suppl):S50-S55. doi:10.1016/j.amepre.2009.04.017

33.Al-Ghamdi SH. The association between watching television and obesity in children of school-age in Saudi Arabia. J Family Community Med. 2013; 20(2):83-89. doi:10.4103/2230-8229.114767

34.Babey SH, Hastert TA, Wolstein J. Adolescent sedentary behaviors: correlates differ for television viewing and computer use. J Adolesc Health. 2013; 52(1):70-76. doi:10.1016/j.jadohealth.2012.05.001

35.Musaiger AO, Awadhalla AS, Al-Mannai M, AlSawad M, Asokan GV. Dietary habits and sedentary behaviors among health science university students in Bahrain. Int $\mathbf{J}$ Adolesc Med Health. 2015.

36.D'Adamo E, Guardamagna O, Chiarelli $\mathrm{F}$, et al. Atherogenic Dyslipidemia and Cardiovascular Risk Factors in Obese Children. nternational Journal of Endocrinology. 2015; 2015: 1-9. Article ID 912047.

37.T. Okamura, "Dyslipidemia and cardiovascular disease: a series of epidemiologic studies in Japanese populations," Journal of Epidemiology, vol. 20, no. 4, pp. 259-265, 2010.

38.Egypt_STEPS_Survey_2017_Facts_and_ Figures.

https://www.who.int/ncds/surveillance/ste ps/Egypt_STEPS_Survey_2017_Facts_and_Fi gures.pdf?ua=1

39. Abdel Wahed WY, El-Khashab K, Hassan SK. Prevalence of Dyslipidemia among Healthy University Students: Fayoum Governorate, Egypt. Epidemiology Biostatistics and Public Health. 2016; 13: e11769:1-9.

40.AlMajed HT, AlAttar AT, Sadek AA, AlMuaili TA,AlMutairi OA, Shaghouli AS, AlTorah WA. Prevalence of dyslipidemia and obesity among college students in 
Kuwait. Alexandria Journal of Medicine. 2011; 47: 67-71.

41. Shawar SM, Al-Bati NA, Al-Mahameed

A, Nagalla DS, Mohammed O. Hypercholesterolemia Among Apparently Healthy University Students Oman Medical Journal. 2012; 27(4): 274-80.

42. Ahmed AM, Elabid BH, Elhassan KH, Waggiallah HA. Metabolic Syndrome among Undergraduate Students Attending Medical Clinics for Obligatory Medical Screening. Tropical Journal of Pharmaceutical Research. 2015; 14(2):317-321.

43. Aboul Ella NAR, Shebab DI, Ismail MA. Prevalence of overweight and obesity, and status of chronic non- communicable diseases and some related risk factors among Egyptian adolescents. J Diabetes Endocrinol 2011; 2: 41-52.

44.Wang, Y., Xu, D. Effects of aerobic exercise on lipids and lipoproteins. Lipids Health Dis. 2017; 16, 132. doi:10.1186/s12944-017-0515-5

45.Mann S, Beedie C, Jimenez A. Differential effects of aerobic exercise, resistance training and combined exercise modalities on cholesterol and the lipid profile: review, synthesis and recommendations. Sports Med. 2014;44(2):211-221. doi:10.1007/s40279013-0110-5

46.Takahashi MM, de Oliveira EP, Moreto F, Portero-McLellan KC, Burini RC. Association of dyslipidemia with intakes of fruit and vegetables and the body fat content of adults clinically selected for a lifestyle modification program. Arch Latinoam Nutr 2010; 60(2):148-54.

47.Farrag A, Eraky AE, Aroussy WE, Sayed G, Mahrous A, et al. Obesity and Other Cardiovascular Risk Factors in Egyptian University Students: Magnitude of the Problem. Epidemiology (sunnyvale). 2015; 5:181.

48. Abolfotouh MA, Sallam SA,.Mohammed MS, Loutfy AA, Hasab AA. Prevalence of Elevated Blood Pressure and Association with Obesity in Egyptian School Adolescents. International Journal of Hypertension. 2011; 2011, Article ID 952537, 8 pages.

49.Guo ZR, Hu XS, Wu M, Zhou MH, Zhou ZY. A Prospective Study on the Association between Dyslipidemia and Hypertension. Chinese Journal of Epidemiology. 2009; 30(6): 554-8

50.López ACC. The double burden of malnutrition: obesity and iron deficiency. $\mathrm{PhD}$ Thesis, Wageningen: Wageningen University. 2015.

51.Sonnwebera T, Ressa C, Nairza M, et al. High-fat diet causes iron deficiency via hepcidin-independent reduction of duodenal iron absorption. The Journal of nutritional biochemistry.2012; 23(12): 1600-1608. DOI: $10.1016 /$ j.jnutbio.2011.10.013

52.GBD 2017 Causes of Death Collaborators. Global, regional, and national age-sex-specific mortality for 282 causes of death in 195 countries and territories, 19802017: a systematic analysis for the Global Burden of Disease Study 2017. Lancet 2018; 392: 1736-88. 